\title{
Medication nonadherence among South American patients with schizophrenia
}

\author{
This article was published in the following Dove Press journal: \\ Patient Preference and Adherence \\ 6 October 2017 \\ Number of times this article has been viewed
}

\author{
Alejandra Caqueo-Urízar ${ }^{1}$ \\ Alfonso Urzúa ${ }^{2}$ \\ Guillaume Fond ${ }^{3,4}$ \\ Laurent Boyer ${ }^{5}$ \\ 'Universidad de Tarapacá, Escuela \\ de Psicología y Filosofía, Arica, \\ Chile; ${ }^{2}$ Universidad Católica del \\ Norte, Avda, Angamos, Antofagasta, \\ Chile; ${ }^{3}$ Université Paris Est-Créteil, \\ Pôle de Psychiatrie des Hôpitaux \\ Universitaires H Mondor, INSERM \\ U955, Eq Psychiatrie Translationnelle, \\ DHU Pe-Psy, France; ${ }^{4}$ Fondation \\ FondaMental Fondation de \\ coopération scientifique en santé \\ mentale, France; ${ }^{5} \mathrm{Aix}-$ Marseille Univ, \\ EA 3279 - Public Health, Chronic \\ Diseases and Quality of Life - \\ Research Unit, Marseille, France
}

Objective: The objective of this research was to quantify nonadherence to medication and explore the determinants of nonadherence in patients diagnosed with schizophrenia (SZ) from three countries in Latin America (Bolivia, Peru, and Chile).

Methods: This study was conducted in public mental health centers in Bolivia, Peru, and Chile. The data collected included drug attitude inventory (DAI-10), sociodemographic information, and clinical and treatment characteristics of patients with SZ. Multivariate analysis with multiple linear regression was then performed to identify variables that were potentially associated with the DAI score (dependent variable).

Results: Two hundred and fifty-three patients diagnosed with SZ participated in the study and 247 fully completed the DAI-10. In the multivariate analysis, medication nonadherence was associated with being a woman $(\beta=-0.16, p=0.029)$, younger age $(\beta=0.17, p=0.020)$, younger age at onset of disease $(\beta=-0.17, p=0.019)$, and lower insight $(\beta=-0.30, p<0.001)$.

Conclusion: Being a female, younger age, younger age at onset of disease, and lower insight were the main features associated with nonadherence. If future longitudinal studies confirm these findings, these factors should not be neglected in Latin American mental health public policies to address the problem of nonadherence.

Keywords: medication adherence, schizophrenia, gender, insight

\section{Introduction}

The antipsychotic medication has been shown to reduce the symptoms and the relapses associated with schizophrenia (SZ). ${ }^{1}$ Despite these benefits, the rates of nonadherence vary between $20 \%$ and $89 \%,{ }^{2-10}$ thus being the greatest obstacle in the management of the disorder. ${ }^{2}$

In schizophrenic patients, when antipsychotic drug therapy is discontinued, the risk of relapse increases almost five times. ${ }^{11}$ It also results in worsening of symptoms, suicidal attempts, and consequently, repeated emergency room visits or rehospitalization. ${ }^{11,12}$

Adherence is defined as "the degree to which a patient's behavior, in relation to taking medication, following a diet, or modifying lifestyle habits, corresponds to the recommendations agreed with the health professional". ${ }^{13}$ On the other hand, the term compliance is related to a more passive and submissive behavior of the patient to obey a prescription. The lack of participation in the definition, according to Dilla et al, ${ }^{14}$ would be evidencing less use of the term compliance, although in the clinic both concepts are used interchangeably.

Nonadherence to pharmacological treatment in patients with SZ is a complex phenomenon summarized into the following four factors: sociodemographic variables; variables related with the disorder itself; variables related to treatment (frequency and intensity of side effects, insight, comorbid addiction, and duration of treatment);

\footnotetext{
Correspondence: Alejandra

Caqueo-Urízar

Universidad de Tarapacá, Escuela de

Psicología y Filosofía, Avenida 18 de

Septiembre 2222, Arica, Chile

Tel +56582205622

Fax +56 582205818

Email acaqueo@uta.cl
} 
and finally, variables that have to do with the values and attitudes of the patient (attitude toward the disease). ${ }^{15-18}$

Previous studies have found that young, male patients with low socioeconomic level, belonging to a minority, with poor social functioning and difficulties in the establishment of an adequate therapeutic alliance present greater difficulties to achieve adherence to the treatment. ${ }^{8,19}$

Knowing the risk factors related to lack of adherence is important because the modification of these factors can become targets for future treatments, ${ }^{11}$ especially in Latin American countries where research on this topic is scarce.

The objective of this research was to quantify nonadherence to medication and explore the determinants of nonadherence in patients diagnosed with SZ from three main regions in Latin America. These three Latin American countries share several cultural characteristics; however, there are some general differences between them, which should be made explicit: in Bolivia, $13.6 \%$ of the population lives with less than US\$1 per day; in Peru, this population is 5.9\%; and it is $<2.0 \%$ in Chile, which shows some difference in relation to the poverty index. ${ }^{20}$

Other differences are associated with psychiatric care facilities: per 100,000 inhabitants, Bolivia has 0.1 psychiatric hospitals, Peru has 0.01, and Chile has 0.003 (this country has a greater number of outpatient institutions), mental health staff (the number of psychiatrists in Bolivia is 0.1; Peru: 0.1 and Chile: 0.6 per 100,000 inhabitants); lack of day hospitals (Bolivia, 0.1; Peru, 0; and Chile, 0.5), and residential care (Bolivia, 0; Peru, without data; and Chile, 103)..$^{21,22}$

In relation to each specific institution in this study, the three clinics shared similar characteristics in terms of size, type of treatment given to patients, professionals, and free access to care.

\section{Methods}

\section{Study participants}

This cross-sectional study analyzed the information obtained through interviews and surveys of patients diagnosed with SZ attending the Public Mental Health Centers in three Latin American cities: La Paz, Bolivia (32.8\%); Arica, Chile (33.6\%); and Tacna, Peru (33.6\%). The Mental Health Centers selected were the largest in each region. The first author reviewed the total number of patients diagnosed with SZ who were treated each service; subsequently, clinical psychologists made the interviews over a 3-month period in each city. Patients were invited to participate as they came for their monthly follow-up visits. A set of exclusion criteria to the selection of patients was applied (being in a state of psychotic crisis or having a sensory or cognitive type of disorder that prevents being evaluated) to ensure their ability to participate fully in the interviews. As most of the patients were stable, in relation to their psychotic symptomatology, the number of patients excluded was low and also the overwhelming majority of the people agreed to participate.

The final sample included 253 patients with an ICD-10 diagnosis of SZ. ${ }^{23}$

\section{Procedures}

The study was approved by the Ethics Committee of the University of Tarapacá and the National Health Service of Chile. We also obtained the authorization of the Public Mental Health Services in Peru and Bolivia. Two psychologists, who were part of the research team and supervised by the principal researcher, conducted the survey of the patients under the auspices of the mental health services of each country. The length of time of the evaluation was between 20 and $30 \mathrm{~min}$.

Before the start of the survey, written informed consent was requested and received from the patients. The objectives of the study were explained as well as the voluntary nature of participation. No compensation was offered for participating in the study.

\section{Measures}

\section{Drug attitude inventory}

This 10-item self-report scale was developed to assess attitude, experience, and beliefs about antipsychotic drugs. ${ }^{24}$ The drug attitude inventory (DAI-10) is considered to be a good predictor of adherence to treatment in SZ. ${ }^{24,25}$ Scores ranged from -10 (very poor attitude) to +10 (best possible attitude). This is a simple and easy-to-use self-report instrument with good psychometric properties that assess a unique clinical dimension relevant to nonadherence. ${ }^{25}$ DAI-10 scores that are analyzed here were obtained from patients.

Patients with a score of 6-10 are considered as adherent, from 0 to 5 as moderate, and in negative ranges are considered as nonadherent. ${ }^{26}$ This instrument has a Spanish version carried out by Ramírez et al. ${ }^{27}$ In relation to its psychometric properties, this instrument shows an inter-rater reliability index of $0.61(p<0.001)$ and an internal consistency coefficient of 0.57 . The version of the DAI shows convergent validity as well as moderate reliability. ${ }^{27}$

\section{Positive and negative syndrome scale for SZ}

This 30-item, 7-point (1-7) clinician rating scale assesses psychotic symptoms in individuals with SZ. ${ }^{28}$ For the purposes 
of this study, we considered the five subscales of the positive and negative syndrome scale for schizophrenia (PANSS): positive, negative, excitation, depression, and cognitive subscales. ${ }^{29}$ Higher scores indicate more severe symptomatology. The PANSS has been translated and validated in Spain by Peralta and Cuesta, ${ }^{30}$ and Fresán et al ${ }^{31}$ examined the psychometric properties of this instrument in Mexico. PANSS severity scores are: PANSS total score of $58=$ mildly ill, 75= moderately ill, 95= markedly ill, and 116= severely ill.

Barnes akathisia scale (BAS) ${ }^{32}$ was used to evaluate akathisia. BAS contains four items, including objective akathisia, subjective awareness of restlessness, subjective distress related to restlessness, and a global clinical assessment of akathisia. In this study, we used the global clinical assessment of akathisia. Higher scores indicate more severe akathisia.

\section{Simpson-Angus extrapyramidal side effect scale} Simpson-Angus extrapyramidal side effect scale (SAS) was used to evaluate extrapyramidal symptoms. The scale contains 10 items rated on a scale of $0-4 .{ }^{33}$ Higher scores indicate more severe extrapyramidal symptoms.

Finally, insight was measured by the psychiatrist using the abbreviated version of the scale to assess unawareness in mental disorder (SUMD). ${ }^{34,35}$ In this study, we examined the awareness of disease, higher scores representing unawareness.

\section{Clinical and demographic data}

The clinical variables included: the number of hospitalizations in the last 3 years, age at onset of the disorder (defined as the age that the first acute psychotic episode appeared), the presence or absence of add-on integrated treatment (defined by psychotherapy, family psychoeducation, and/or day care hospital in addition to pharmacological treatment). All patients were administered antipsychotics. The demographic variables assessed were sex, age, marital status ( single or in couple), educational level ( $\geq 12$ years or $<12$ ), employment status (unemployed or employed), ethnicity (Aymara and non-Aymara), and family income (measure of the total salary per month for all members of the family, expressed in US dollars).

Concerning ethnicity, the Aymara is the largest ethnic group in these regions of Latin America, with a total population of two million people, and has lived in the Andes Mountains for centuries. Recent generations of Aymara have undertaken a massive migration from rural towns to large cities and, thus, receive healthcare services from the same clinics as non-Aymara individuals. ${ }^{36-39}$

\section{Statistical analysis}

Descriptive analyses are presented as frequencies and percentages for categorical variables and as means and SDs for continuous variables. Associations between DAI score and the continuous variables were analyzed via Spearman's correlation tests. Means-based comparisons of the DAI scores between various subgroups were calculated via Mann-Whitney tests. Multivariate analysis with multiple linear regression (simultaneous model) was then performed to identify variables that were potentially associated with the DAI score (dependent variable). The variables that were relevant to the models were selected from the univariate analysis based on a threshold $p$-value of $\leq 0.10$. Gender was included in the model because of its association with nonadherence in previous studies. The final models incorporated the standardized $\beta$ coefficients, which represent a change in the standard deviation of the dependent variable (DAI) resulting from a change of one standard deviation in the various independent variables. The independent variables with the higher standardized beta coefficients are those with a greater relative effect on multivariate adaptive regression splines.

All of the tests were two sided. Statistical significance was defined as $p<0.05$. The statistical analysis was performed with SPSS Statistics for Windows, version 20.0 (SPSS Inc., Chicago, IL, USA).

\section{Results}

Two hundred fifty-three patients with SZ participated in the study and 247 fully completed the DAI-10. The mean age was 35.6 years $(\mathrm{SD}=15.5) ; 66.4 \%$ were male and $46.2 \%$ of the patients were Aymara, 93.6\% of the patients were not married or without a partner, $68.8 \%$ had no occupation, and $84.2 \%$ had low educational level ( $\leq 12$ years). DAI-10 scores reflect a moderate adherence to the medication (3.0, $\mathrm{SD}=4.8)$. Overall, 49 (19.8\%) participants were considered as nonadherent. The prevalence of nonadherence was $11.8 \%$ in Chile, $25.0 \%$ in Peru, and 23.2\% in Bolivia.

The severity of the symptoms was moderate, with a total PANSS score of 71.3 ( $\mathrm{SD}=28.2$ ). The mean in the BAS was 0.9 ( $\mathrm{SD}=2.0)$ below the cutoff score for the diagnosis of akathisia. The mean score in the SAS was $1.9(\mathrm{SD}=2.5)$. All data are presented in Table 1.

Bivariate and multivariate analyses results are reported in Table 2. In the bivariate analysis, nonadherence was associated with younger age $(p=0.003)$, country $(p=0.032$, the lowest adherence was found in Peru), lower monthly family income ( $p=0.039)$, higher severity of psychotic symptoms including the total PANSS index $(p<0.001)$ and all the PANSS factors, lower awareness of disease $(p<0.001)$, 
Table I Sample characteristics

\begin{tabular}{|c|c|}
\hline Characteristics & M (SD) \\
\hline Gender (female) (\%) & 33.6 \\
\hline Age (years) & $35.6(15.5)$ \\
\hline \multicolumn{2}{|l|}{ Ethnicity (\%) } \\
\hline Aymara & 46.2 \\
\hline Non-Aymara & 53.8 \\
\hline Educational level ( $\geq 12$ years) $(\%)$ & 15.8 \\
\hline \multicolumn{2}{|l|}{ Marital status (\%) } \\
\hline Single & 93.6 \\
\hline Couple & 6.4 \\
\hline \multicolumn{2}{|l|}{ Employment status (\%) } \\
\hline Unemployed & 68.8 \\
\hline Employed & 31.2 \\
\hline Monthly family income (USD dollars) & $417.6(429.4)$ \\
\hline Age at onset of the disorder (years) & $20.9(6.5)$ \\
\hline \multicolumn{2}{|l|}{ PANSS } \\
\hline Positive factor & $8.3(4.6)$ \\
\hline Negative factor & $18.6(8.4)$ \\
\hline Cognitive factor & $7.3(4.0)$ \\
\hline Depressive factor & $6.4(3.7)$ \\
\hline Excitement factor & $11.5(5.9)$ \\
\hline PANSS Total & $71.3(28.2)$ \\
\hline SUMD & $7.1(4.4)$ \\
\hline Number of hospitalizations in the last 3 years & $1.2(1.5)$ \\
\hline \multicolumn{2}{|l|}{ Type of mental health treatment (\%) } \\
\hline Only pharmacological & 87.7 \\
\hline Pharmacological + psychotherapy & 12.3 \\
\hline SAS & $1.9(2.5)$ \\
\hline BAS & $0.9(2.0)$ \\
\hline DAI & $3.0(4.8)$ \\
\hline
\end{tabular}

Notes: M (SD): mean (standard deviation); (\%): effective (percentage). PANSS severity - PANSS total score of 58= mildly ill, 75= moderately ill, 95= markedly ill, and I I6= severely ill; SUMD - the higher the score, the lower the insight; SAS - the higher the score, the higher the pseudoparkinsonism; BAS - the higher the score, the higher the akathisia; DAI - the higher the score, the better the attitude toward medication.

Abbreviations: BAS, Barnes akathisia scale; DAI, drug attitude inventory; PANSS, positive and negative syndrome scale for schizophrenia; SAS, Simpson-Angus extrapyramidal side effect scale; SUMD, scale to assess unawareness in mental disorder.

pharmacological treatment only $(p<0.001)$, and the presence of side effects measured by the SAS $(p=0.021)$ and the $\operatorname{BAS}(p=0.011)$.

In the multivariate analysis, nonadherence was significantly associated with female gender $(\beta=-0.16 ; p=0.029)$, younger age $(\beta=0.17 ; p=0.020)$, younger age at onset of the disorder $(\beta=0.17 ; p=0.029)$, and lower awareness of disease $(\beta=-0.030 ; p<0.001)$.

\section{Discussion}

The major findings of the present study may be summarized as follows: in a large multicenter sample of Latin American community-dwelling SZ patients from three countries, medication nonadherence was associated with being a woman, younger age, younger age at onset of disease, and lower insight. In relation to this last point, as found by a recent study, it is likely that patients who struggled with medication had a difficult time acknowledging their illness..$^{18}$ On the other hand, several factors did not remained significant after adjustment such as country, monthly family income, more severe psychotic symptomatology, type of mental health treatment, and side effects.

The association between nonadherence and female gender is one of the major findings of the present study confirming a recent study performed in France. ${ }^{40} \mathrm{~A}$ possible reason for this finding is the fact that drugs may not be as efficient and tolerated by female as by male. ${ }^{41-43}$ Differences in the physiology of male and female and in their response to treatment have been reported, and male research subjects continue to dominate biomedical studies. ${ }^{44}$ Research has been negligent in properly incorporating the participation of female; ${ }^{45}$ so if research excludes female, then the guidelines are made mainly from male, ${ }^{46}$ generating a significant inequity in health. In particular, most of the antipsychotic drugs are developed in middle-aged, mean-weighted male to avoid the issue of pregnancy. However, the biological differences between male and female affect the action of many drugs.

Female have lower body weights and organ sizes, more body fat, different gastric motility characteristics, and a lower glomerular filtration rate in comparison to male. ${ }^{47}$ The hepatic enzyme CYP3A4 is more active in female than in male, which leads to different effects on drug metabolism. ${ }^{48}$ All these differences are known to affect the pharmacokinetics and pharmacodynamics of the drugs, explaining that gender can play a major role in efficiency and adverse drug reactions. Specific pharmacological and nonpharmacological treatment strategies could thus be developed for female with SZ. Another hypothesis cannot be excluded from our study: deficit in female's access to treatment. In LatinAmerica and Caribe, there are still important inequalities in mental health, especially with severe disorders such as SZ (63\% of these people do not receive any treatment), ${ }^{49}$ and the main differences are related to being poor, living in rural areas, and being a woman. ${ }^{50}$ These inequalities, particularly for female, must therefore be considered in health policies.

The other findings of our study are in line with previous studies on adherence in SZ patients. Younger age and younger age of onset were associated with nonadherence. ${ }^{8,16,51}$ Several hypotheses have been formulated to explain these findings. Younger patients may be less adherent because they may not be aware of the severity of the disorder or the need to maintain pharmacological treatment, thus tending to drug abuse. ${ }^{52}$ 
Table 2 Sociodemographic and clinical characteristics associated with medication adherence $(\mathrm{n}=247)$

\begin{tabular}{|c|c|c|c|c|}
\hline \multirow[t]{2}{*}{ Characteristics } & \multicolumn{2}{|l|}{ Univariate analysis } & \multicolumn{2}{|c|}{ Multivariate analysis } \\
\hline & $\begin{array}{l}\text { DAl score M (SD)* } \\
\text { or } R^{* *}\end{array}$ & p-value & $\beta^{* * * *}$ & $p$-value \\
\hline \multicolumn{5}{|l|}{ Gender } \\
\hline Male & $3.2(4.8)$ & 0.349 & -0.16 & 0.029 \\
\hline Female & $2.6(4.9)$ & & & \\
\hline Age (years)* & 0.19 & 0.003 & 0.17 & 0.020 \\
\hline \multicolumn{5}{|l|}{ Ethnicity } \\
\hline Aymara & $2.6(4.9)$ & 0.112 & - & - \\
\hline Non-Aymara & $3.9(5.3)$ & & & \\
\hline \multicolumn{5}{|l|}{ Educational level } \\
\hline Low (<12 years) & $3.0(4.9)$ & 0.799 & - & - \\
\hline High ( $\geq 12$ years) & $3.4(4.3)$ & & & \\
\hline \multicolumn{5}{|l|}{ Marital status } \\
\hline Single & $3.1(4.8)$ & 0.401 & - & - \\
\hline Couple & $2.1(5.1)$ & & & \\
\hline \multicolumn{5}{|l|}{ Employment status } \\
\hline Unemployed & $2.8(4.9)$ & 0.235 & - & - \\
\hline Employed & $3.5(4.8)$ & & & \\
\hline \multicolumn{5}{|l|}{ Country } \\
\hline Peru & $2.0(4.5)$ & 0.032 & - & - \\
\hline Bolivia & $3.2(5.2)$ & & 0.15 & 0.109 \\
\hline Chile & $3.9(4.5)$ & & 0.01 & 0.925 \\
\hline Monthly family income (USD) & 0.14 & 0.039 & 0.08 & 0.259 \\
\hline Age at onset of the disorder (years)* & 0.12 & 0.069 & 0.17 & 0.019 \\
\hline Severity - PANSS total score* & -0.31 & $<0.001$ & -0.18 & 0.062 \\
\hline Positive factor & -0.28 & $<0.001$ & & \\
\hline Negative factor & -0.20 & $<0.001$ & & \\
\hline Cognitive factor & -0.24 & $<0.001$ & & \\
\hline Depressive factor & -0.23 & $<0.001$ & & \\
\hline Excitement factor & -0.26 & $<0.001$ & & \\
\hline SUMD & -0.39 & $<0.001$ & -0.30 & $<0.001$ \\
\hline Number of hospitalizations in the last 3 years & -0.08 & 0.191 & - & - \\
\hline \multicolumn{5}{|l|}{ Type of mental health treatment } \\
\hline Pharmacological treatment only & $2.7(4.8)$ & $<0.001$ & 0.05 & 0.647 \\
\hline $\begin{array}{l}\text { Pharmacological + psychotherapy/social } \\
\text { treatment }\end{array}$ & $5.4(4.5)$ & & & \\
\hline SAS & -0.15 & 0.021 & 0.04 & 0.640 \\
\hline BAS & -0.16 & 0.011 & 0.02 & 0.818 \\
\hline
\end{tabular}

Notes: *M (SD), mean (standard deviation); **R, Pearson's correlation coefficient; *** $\beta$, standardized beta coefficient ( $\beta$ represents a change in the standard deviation in the DAl score resulting from a one standard deviation change in the independent variable). Bold values: $p<0.05$.

Abbreviations: BAS, Barnes akathisia scale; DAI, drug attitude inventory; PANSS, positive and negative syndrome scale for schizophrenia; SAS, Simpson-Angus extrapyramidal side effects scale; SUMD, scale to assess unawareness of mental disorder.

Patients with younger age on onset may be less adherent because they tend to have more neurocognitive impairments, functional disabilities, positive and negative symptoms, and less responsiveness to antipsychotic medications. ${ }^{53,54} \mathrm{In}$ addition, these two features of nonadherence are important to consider because the onset of SZ and other psychiatric disorders begins before the age of 30 and effective treatment is not initiated until years later. ${ }^{55}$ Previous studies have reported that a longer duration of untreated psychosis was associated with poor adherence ${ }^{11,56}$ and may be related to worse treatment outcome as a result of the toxic effects of the psychosis experience. ${ }^{57}$ Patient's age and age of onset are thus critical features that should be considered in orienting health intervention and, more largely, health policies in Latin America on prevention and early intervention and the organization of mental health care for patients with SZ.

Lack of insight was also an important feature of nonadherence in our study. The association between lack of insight and poor adherence has been extensively confirmed in previous studies. ${ }^{11,18,58-62}$ This finding suggests that clinicians should enhance the detection of this problem of insight in Latin American countries and try to modify 
attitudes toward medication in SZ patients, especially by exploring and addressing concerns and patients' distrust in pharmacotherapy. ${ }^{59}$ Previous studies reported the importance of respecting and considering patients' belief systems to improve medication attitudes. ${ }^{22}$ Other sociodemographic and clinical variables were not related to adherence, as obtained by Lacro et al..$^{5}$ This result is similar to previous studies as well that the side effects to the medication had impact on DAI-10 scores. ${ }^{11,17,63-65}$

The study presents limitations. First, the cross-sectional design used in this research does not allow causal relationships to be established, so longitudinal studies are necessary. Second, the behavior of patients in relation to pharmacological adherence is not easy to detect and quantify, and all forms of detection have some limitations. In fact, the DAI scale is criticized because it assesses adherence subjectively as opposed to other more quantifiable methods such as pill counts, electronic monitor, and plasma concentrations. However, as suggested by Velligan et al, ${ }^{66}$ even the use of more objective measures can be associated with significant errors. In addition, the 10-item DAI is easy to administer, is widely used, has good psychometric properties, and has been shown to predict adherence. ${ }^{11,25,67}$ Third, the study did not have a classification based on the type of antipsychotic used by patients; future investigations should consider differentially between the effects of first and second generation of antipsychotics, as well as incorporate other elements related to adherence, such as therapeutic alliance, time of untreated psychosis, family and social support. On the other hand, the information obtained did not allow the consideration of the psychosocial components or the psychoeducational needs of the subjects, which are factors that are associated with the therapeutic adherence.

\section{Conclusion}

Nonadherence remains a challenging problem in SZ in Latin American countries.

Being a woman, younger age, younger age at onset of disease, and lower insight are the main features associated with nonadherence in this study performed in Latin America.

If future longitudinal studies confirm these findings, these factors should not be neglected in Latin American mental health public policies to address the problem of nonadherence.

\section{Acknowledgment}

This project was funded by the University of Tarapacá through the Major Project of Scientific and Technological Research UTA no 3732-16.

\section{Disclosure}

The authors report no conflicts of interest in this work.

\section{References}

1. Gilmer TP, Ojeda VD, Barrio C, et al. Adherence to antipsychotics among Latinos and Asians with schizophrenia and limited English proficiency. Psychiatr Serv. 2009;60(2):175-182.

2. Nitzan U, Bukobza G, Aviram S, et al. Rebelliousness in patients suffering from schizophrenia-spectrum disorders - a possible predictor of adherence. Psychiatr Res. 2013;209(3):297-301.

3. Fenton WS, Blyler CR, Heinssen RK. Determinants of medication compliance in schizophrenia: empirical and clinical findings. Schizophr Bull. 1997;23(4):637-651.

4. Jeste SD, Patterson TL, Palmer BW, Dolder CR, Goldman S, Jeste DV. Cognitive predictors of medication adherence among middle-aged and older outpatients with schizophrenia. Schizophr Res. 2003; 63(1-2):49-58.

5. Lacro JP, Dunn LB, Dolder CR, Leckband SG, Jeste DV. Prevalence of and risk factors for medication nonadherence in patients with schizophrenia: a comprehensive review of recent literature. J Clin Psychiatry. 2002;63(10):892-909.

6. Razali MS, Yahya H. Compliance with treatment in schizophrenia: a drug intervention program in a developing country. Acta Psychiatr Scand. 1995;91(5):331-335.

7. Sun SX, Liu GG, Christensen DB, Fu AZ. Review and analysis of hospitalization costs associated with antipsychotic nonadherence in the treatment of schizophrenia in the United States. Curr Med Res Opin. 2007;23(10):2305-2312.

8. Velligan DI, Weiden PJ, Sajatovic M, et al; Expert Consensus Panel on Adherence Problems in Serious and Persistent Mental Illness. The expert consensus guideline series: adherence problems in patients with serious and persistent mental illness. J Clin Psychiatry. 2009;70(Suppl 4):1-46.

9. Young JL, Zonana HV, Shepler L. Medication noncompliance in schizophrenia: codification and update. Bull Am Acad Psychiatry Law. 1986;14(2):105-122.

10. Lieberman JA, Stroup TS, McEvoy JP, et al; Clinical Antipsychotic Trials of Intervention Effectiveness (CATIE) Investigators. Effectiveness of antipsychotic drugs in patients with chronic schizophrenia. N Engl J Med. 2005;353(12):1209-1223.

11. Dassa D, Boyer L, Benoit M, Bourcet S, Raymondet P, Bottai T. Factors associated with medication non-adherence in patients suffering from schizophrenia: a cross-sectional study in a universal coverage healthcare system. Aust N Z J Psychiatry. 2010;44(10):921-928.

12. Jiang $\mathrm{Y}, \mathrm{Ni}$ W. Estimating the impact of adherence to and persistence with atypical antipsychotic therapy on health care costs and risk of hospitalization. Pharmacotherapy. 2015;35(9):813-822.

13. World Health Organization. Adherence to long-term therapies evidence for action. World Health Organization. 2003:107-114. Available from: http:// www.who.int/bookorders/anglais/detart 1 .isp? sesslan=1\&codlan=1\& codcol=15\&codcch-526. Accessed October 19, 2010.

14. Dilla T, Valladares A, Lizán L, Sacristán JA. Adherencia y persistencia terapéutica: causas, consecuencias y estrategias de mejora [Adherence and therapeutic persistence: causes, consequences and improvement strategies]. Aten Primaria. 2009;41(6):342-348. Spanish.

15. Medina E, Salvà J, Ampudia R, Maurino J, Larumbe J. Short-term clinical stability and lack of insight are associated with a negative attitude towards antipsychotic treatment at discharge in patients with schizophrenia and bipolar disorder. Patient Prefer Adherence. 2012;6: 623-629.

16. Fleischhacker WW, Oehl MA, Hummer M. Factors influencing compliance in schizophrenia patients. J Clin Psychiatry. 2003; 64(Suppl 16):10-13.

17. Vassileva IV, Milanova VK. Attitudes toward antipsychotic medication, insight and psychopathology in outpatients with schizophrenia. Folia Med (Plovdiv). 2012;54(4):62-68.

18. Hernandez M, Barrio C. Families and medication use and adherence among Latinos with schizophrenia. J Ment Health. 2017;26(1):14-20. 
19. Czobor P, Van Dorn RA, Citrome L, Kahn RS, Fleischhacker WW, Volavka J. Treatment adherence in schizophrenia: a patient-level meta-analysis of combined CATIE and EUFEST studies. Eur Neuropsychopharmacol. 2015;25(8):1158-1166.

20. Organización Mundial de la Salud. (2013). Estadísticas sanitarias mundiales 2013 [2013 World Health Statistics]. Available from: http://www. who.int/gho/publications/world_health_statistics/2013/es/. Accessed April 1, 2014.

21. Organización Panamericana de la Salud. WHO-AIMS: Informe Regional sobre los sistemas de salud mental en América Latina y el Caribe [Regional report on systems of mental health in Latin America and the Caribbean]. Oficina Sanitaria Panamericana, Oficina Regional de la Organización Mundial de la Salud. Available from: http:// mhpss.net/wpcontent/uploads/group-documents/226/1392656131WHOAIMS_Sistemasaludmental_2013.pdf

22. Caqueo-Urízar A, Boyer L, Baumstarck K, Gilman SE. The relationships between patients' and caregivers' beliefs about the causes of schizophrenia and clinical outcomes in Latin American countries. Psychiatry Res. 2015;229(1-2):440-446.

23. World Health Organization. ICD-10 Classifications of Mental and Behavioural Disorder: Clinical Descriptions and Diagnostic Guidelines. Geneva: World Health Organization; 1992.

24. Hogan TP, Awad AG, Eastwood R. A self-report scale predictive of drug compliance in schizophrenics: reliability and discriminative validity. Psychol Med. 1983;13(1):177-183.

25. Nielsen RE, Lindström E, Nielsen J, Levander S. DAI-10 is as good as DAI-30 in schizophrenia. Eur Neuropsychopharmacol. 2012;22(10): 747-750.

26. Saleem F, Hassali MA, Shafie AA, Awad AG, Bashir S. Association between knowledge and drug adherence in patients with hypertension in Quetta, Pakistan. Trop J Pharm Res. 2011;10(2):125-132.

27. Ramírez Barreto F, Robles García R, Salazar Alvarado V, Páez Agraz F. Evaluación de actitudes al medicamento en pacientes con esquizofrenia propiedades psicométricas de la versión en español del DAI. Actas Esp Psiquiatr. 2004;32(3):138-142.

28. Kay SR, Fiszbein A, Opler LA. The positive and negative syndrome scale (PANSS) for schizophrenia. Schizophr Bull. 1987;13(2):261-276.

29. Lancon C, Auquier P, Nayt G, Reine G. Stability of the five-factor structure of the Positive and Negative Syndrome Scale (PANSS). Schizophr Res. 2000;42(3):231-239.

30. Peralta V, Cuesta MJ. Validación de la Escala de los Síndromes Positivo y Negativo (PANSS) en una muestra de esquizofrénicos españoles. [Validation of the positive and negative syndrome scale (PANSS) in a sample of Spanish schizophrenic]. Actas Luso Esp Neurol Psiquiatr Cienc Afines. 1994;22(4):171-177.

31. Fresán A, De la Fuente-Sandoval C, Loyzaga C, et al. A forced fivedimensional factor analysis and concurrent validity of the positive and negative syndrome scale in Mexican schizophrenic patients. Schizophr Res. 2005;72(2-3):123-129.

32. Barnes TR. A rating scale for drug-induced akathisia. Br J Psychiatry. 1989;154:672-676.

33. Simpson GM, Angus JW. A rating scale for extrapyramidal side effects. Acta Psychiatr Scand Suppl. 1970;212:11-19.

34. Amador XF, Strauss DH. Poor insight in schizophrenia. Psychiatr $Q$. 1993;64:305-318.

35. Michel P, Baumstarck K, Auquier P, et al. Psychometric properties of the abbreviated version of the scale to assess unawareness in mental disorder in schizophrenia. BMC Psychiatry. 2013;13:229.

36. Köster G. Los Aymaras: Características demográficas de un grupo étnico indígena antiguo en los Andes centrales [The Aymara: Demographic characteristics of an ancient indigenous ethnic group in the Central Andes]. In: Van den Berg H, Schiffers N, editors. La Cosmovisión Aymara. La Paz, Bolivia: UCB/Hisbol; 1992:81-111.

37. Van Kessel J. La cosmovisión Aymara. In: Hidalgo J, Schiappacasse F, Niemeyer F, Aldunate C, Mege P, editors. Etnografia: Sociedades Indígenas Contemporáneas y Su Ideología. [Ethnography: Contemporary indigenous societies and their ideology] Santiago, Chile: Editorial Andrés Bello; 1996:169-187.
38. Gundermann H, González H, Vergara J. Vigencia y desplazamiento de la lengua aymara en Chile [Force and displacement of the aymara's language in Chile]. Estudio Filológico. 2007;42:123-140.

39. Núñez R, Cornejo C. Facing the sunrise: cultural worldview underlying intrinsic-based encoding of absolute frames of reference in Aymara. Cogn Sci. 2012;36(6):965-991.

40. Tinland A, Zemmour K, Auquier P, et al; French Housing First Study Group. Homeless women with schizophrenia reported lower adherence to their medication than men: results from the French housing first experience. Soc Psychiatry Psychiatr Epidemiol. Epub 2017 Jun 27.

41. Enger C, Weatherby L, Reynolds RF, Glasser DB, Walker AM. Serious cardiovascular events and mortality among patients with schizophrenia. J Nerv Ment Dis. 2004;192(1):19-27.

42. Goff DC, Sullivan LM, McEvoy JP, et al. A comparison of ten-year cardiac risk estimates in schizophrenia patients from the CATIE study and matched controls. Schizophr Res. 2005;80(1):45-53.

43. Goldstein JM, Cohen LS, Horton NJ, et al. Sex differences in clinical response to olanzapine compared with haloperidol. Psychiatry Res. 2002; 110(1):27-37.

44. Putting gender on the agenda. Nature. 2010;465(7299):665.

45. Walden R. Gender bias in research. J R Soc Med. 2007;100(2):66.

46. Holdcroft A. Gender bias in research: how does it affect evidence based medicine? J R Soc Med. 2007;100(1):2-3.

47. Goldberg R, Rubinstein AM, Gil N, et al. Role of heparanase-driven inflammatory cascade in pathogenesis of diabetic nephropathy. Diabetes. 2014;63(12):4302-4313.

48. El-Eraky H, Thomas SH. Effects of sex on the pharmacokinetic and pharmacodynamic properties of quinidine. Br J Clin Pharmacol. 2003; 56(2):198-204.

49. Kohn R, Levav I, de Almeida JM, et al. Los trastornos mentales en América Latina y el Caribe: asunto prioritario para la salud pública [Mental disorders in Latin America and the Caribbean: priority issue for public health]. Rev Panam Salud Publica. 2005;18(4-5):229-240. Spanish.

50. Rodríguez J, Kohn R, Aguilar-Gaxiola S. Epidemiología de Los Trastornos Mentales en América Latina y el Caribe. Washington, DC: OPS; 2009.

51. Lang K, Meyers JL, Korn JR, et al. Medication adherence and hospitalization among patients with schizophrenia treated with antipsychotics. Psychiatr Serv. 2010;61(12):1239-1247.

52. Kessler RC, McGonagle KA, Zhao S, et al. Lifetime and 12-month prevalence of DSM-III-R psychiatric disorders in the United States: Results from the National Comorbidity Survey. Arch Gen Psychiatry. 1994;51(1):8-19.

53. Bellino S, Rocca P, Patria L, et al. Relationships of age at onset with clinical features and cognitive functions in a sample of schizophrenia patients. J Clin Psychiatry. 2004;65(7):908-914.

54. Tuulio-Henriksson A, Partonen T, Suvisaari J, Haukka J, Lönnqvist J. Age at onset and cognitive functioning in schizophrenia. Br J Psychiatry. 2004;185:215-219.

55. McGorry PD, Purcell R, Goldstone S, Amminger P. Age of onset and timing of treatment for mental and substance use disorders: implications for preventive intervention strategies and models of care. Curr Opin Psychiatry. 2011;24(4):301-306.

56. Dassa D, Boyer L, Raymondet P, Bottai T. One or more durations of untreated psychosis? Acta Psychiatr Scand. 2011;123(6):494.

57. Norman RM, Malla AK. Duration of untreated psychosis: a critical examination of the concept and its importance. Psychol Med. 2001;31(3): 381-400.

58. Baloush-Kleinman V, Levine SZ, Roe D, Shnitt D, Weizman A, Poyurovsky M. Adherence to antipsychotic drug treatment in earlyepisode schizophrenia: a six-month naturalistic follow-up study. Schizophr Res. 2011;130(1-3):176-181.

59. Beck EM, Cavelti M, Kvrgic S, Kleim B, Vauth R. Are we addressing the "right stuff" to enhance adherence in schizophrenia? Understanding the role of insight and attitudes towards medication. Schizophr Res. 2011;132(1):42-49. 
60. Boyer L, Aghababian V, Richieri R, et al. Insight into illness, neurocognition and quality of life in schizophrenia. Prog Neuropsychopharmacol Biol Psychiatry. 2012;36(2):271-276.

61. Jonsdottir H, Opjordsmoen S, Birkenaes AB, et al. Predictors of medication adherence in patients with schizophrenia and bipolar disorder. Acta Psychiatr Scand. 2013;127(1):23-33.

62. Novick D, Montgomery W, Treuer T, Aguado J, Kraemer S, Haro JM. Relationship of insight with medication adherence and the impact on outcomes in patients with schizophrenia and bipolar disorder: results from a 1-year European outpatient observational study. BMC Psychiatry. 2015;15:189.

63. Perkins DO, Johnson JL, Hamer RM, et al; HGDH Research Group. Predictors of antipsychotic medication adherence in patients recovering from a first psychotic episode. Schizophr Res. 2006;83(1):53-63.

64. Perkins DO, Gu H, Weiden PJ, McEvoy JP, Hamer RM, Lieberman JA; Comparison of atypicals in first episode study group. Predictors of treatment discontinuation and medication nonadherence in patients recovering from a first episode of schizophrenia, schizophreniform disorder, or schizoaffective disorder: a randomized, double-blind, flexible dose, multicenter study. J Clin Psychiatry. 2008;69(1): $106-113$.
65. Linden M, Godemann F, Gaebel W, et al. A prospective study of factors influencing adherence to a continuous neuroleptic treatment program in schizophrenia patients during 2 years. Schizophr Bull. 2001;27(4): 585-596.

66. Velligan DI, Lam YW, Glahn DC, et al. Defining and assessing adherence to oral antipsychotics: a review of the literature. Schizophr Bull. 2006;32(4):724-742.

67. Velligan DI, Sajatovic M, Hatch A, Kramata P, Docherty JP. Why do psychiatric patients stop antipsychotic medication? A systematic review of reasons for nonadherence to medication in patients with serious mental illness. Patient Prefer Adherence. 2017;11:449-468.

\section{Publish your work in this journal}

Patient Preference and Adherence is an international, peer-reviewed, open access journal that focuses on the growing importance of patient preference and adherence throughout the therapeutic continuum. Patient satisfaction, acceptability, quality of life, compliance, persistence and their role in developing new therapeutic modalities and compounds to optimize clinical outcomes for existing disease states are major areas of interest for the journal. This journal has been accepted for indexing on PubMed Central. The manuscript management system is completely online and includes a very quick and fair peer-review system, which is all easy to use. Visit http://www dovepress.com/testimonials.php to read real quotes from published authors.

Submit your manuscript here: http://www.dovepress.com/patient-preference-and-adherence-journal 